\begin{tabular}{|c|c|c|}
\hline 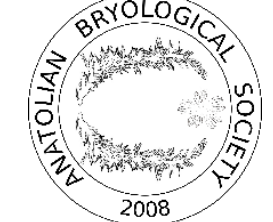 & $\begin{array}{l}\text { http://dergipark.gov.tr/anatolianbryology } \\
\text { Yetgin et al. 2017. Anatolian Bryol. 3(1): 43-47 }\end{array}$ & $\begin{array}{c}\text { Anatolian Bryology } \\
\text { Anadolu Briyoloji Dergisi } \\
\text { Research Article } \\
\text { ISSN:2149-5920 Print } \\
\text { e-ISSN:2458-8474 Online }\end{array}$ \\
\hline
\end{tabular}

Pterigynandrum filiforme Hedw. Türünün Antimikrobiyal Aktivitesinin Belirlenmesi

*Ali YETGIN ${ }^{1}$, Merve ŞENTURAN ${ }^{2}$, Atakan BENEK ${ }^{2}$, Ebru EFE $^{2}$, Kerem CANLI $^{3}$

${ }^{1}$ İzmir Yüksek Teknoloji Enstitüsü, Mühendislik ve Fen Bilimleri Enstitüsü, Biyoteknoloji Bölümü Urla/İzmir

${ }^{2}$ Dokuz Eylül Üniversitesi, Buca Ĕgitim Fakültesi, Biyoloji Öğretmenliği Bölümü Buca/İzir

${ }^{3}$ Dokuz Eylül Üniversitesi, Fen Fakültesi, Biyoloji Bölümü Buca/İzmir

\begin{abstract}
\begin{tabular}{lll}
\hline \hline Received: 15.05.2017 & Revised: 30.05.2017 & Accepted: 04.06.2017 \\
\hline \hline
\end{tabular}
$\ddot{\mathbf{O} z}$

Pterigynandrum filiforme Hedw. Orta Avrupa ve Anadolu'nun dağlık alanlarında orman altlarında yaşayan bir karayosunu türüdür. Yayılış alanı geniş olduğu için bulunması kolaydır. Antimikrobiyal çalışmaların amacı dünya üzerinde enfeksiyon hastalıklarına sebep olan mikroorganizmaların etkilerini yok edebilen maddelerin bulunmasıdır. Yapılan antimikrobiyal aktivite çalışmasıyla $P$. filiforme'nin 17 bakteri ve 1 maya türü üzerindeki etkisi analiz edildi. Etanol ekstraksiyon yöntemi ile 0.27 ve $0.93 \mathrm{mg}$ örnekler hazırlandı ve disk difüzyon yöntemi ile geniş spektrumlu antimikrobiyal analizi yapıldı. P. filiforme karayosununun antimikrobiyal potansiyeli konusunda literatürde herhangi bir araştırma bulunmamaktadır. $P$. filiforme örnekleri ile çalışılan bakterilerde antimikrobiyal etki belirlenmiş̧tir. Bunlar gram pozitif bakteriler olan S. aureus, B. subtilis, L. monocytogenes ve E. faecalis; gram negatif bakteriler olan $K$. pneumoniae ve $S$. enteritidis olmaktadır.
\end{abstract}

Anahtar kelimeler: Pterigynandrum filiforme, briyofit, antimikrobiyal aktivite, etanol ekstrakt, disk difüzyon yöntemi.

\title{
Determination of Antimicrobial Activity of Pterigynandrum filiforme Hedw.
}

\begin{abstract}
Pterigynandrum filiforme Hedw. is a moss species living in the forests of Central Europe and Anatolia. It is a wide spreading moss. The aim of the antimicrobial studies are discovering new substances which reduce effects of infectious. The antimicrobial activity effect of $P$. filiforme against 17 bacteria and 1 fungus species was analyzed in this study. 0.27 and $0.93 \mathrm{mg}$ samples were prepared by ethanol extraction method and wide spectrum antimicrobial analysis was performed by disk diffusion method. There is no research in the literature regarding the antimicrobial potential of $P$. filiforme. Antimicrobial activity was determined in the bacteria treated with $P$. filiforme samples. These include gram-positive bacteria $S$. aureus, B. subtilis, L. monocytogenes and E. faecalis; gramnegative bacteria $K$. pneumoniae and $S$. enteritidis.
\end{abstract}

Key words: Pterigynandrum filiforme, bryophyte, antimicrobial activity, ethanol extract, disk diffusion method.

\footnotetext{
* Corresponding author: ali1992yetgin@ gmail.com

(C) 2017 All rights reserved / Tüm haklarl saklıdır.

To cite this article: Yetgin A. Şenturan M. Benek A. Efe E. Canll A. 2017. Determination of Pterigynandrum filiforme Hedw. Antimicrobial Activity. Anatolian Bryology. 3(1): 43-47
} 


\section{Giriş}

Kullanılan maddelerin in vitro etkinliğini belirlemek amacıyla mikroorganizmalara karşı denenmesi için antimikrobiyal aktivite çalışmaları gerçekleştirilir. $\mathrm{Bu}$ çalışmaların kolay uygulanabiliyor olması ve düşük maliyet gerektirmesi nedeniyle antibiyotik duyarlılı̆̆ının saptanmasında yaygın olarak kullanılmaktadır (Canlı 2016c).

Dünya geneline baktığımızda enfeksiyon kaynaklı ölümlerin artıyor olması gereken çalışmaların çok geç kalınmadan yapılması gerektiğini gösterir. Özellikle tropikal ülkelerde gerçekleşen ölümlerin yaklaşık yarısının enfeksiyon kaynaklı olması durumun boyutunun daha da iyi anlaşılabilmesi adına önemlidir. Sadece E. coli ve Salmonella suşları her yıl Afrika'da 300.000 civarı çocukta enfeksiyon kaynaklı ölüme sebep olmaktadır (Akbar ve Anal, 2011). Amerika Birleşik Devletleri'nde 1981 ve 1992 yıllarında yapılan araştırmaları karşılaştırdığımızda, enfeksiyona bağlı ölümler 5. Sıradan \%58 artışla 3. sıraya yükselmiştir (Iwu, 1999; Karou, 2007). Bu durum enfeksiyon hastalıklarının önlenmesi ve tedavisinde yeni stratejiler geliştirmeyi zorunlu kılmıştır (Erdoğan ve Everest, 2013).

Antibiyotik direnci olan bakterilerin hızla yaygınlaşması ve kullanılan tüm antibiyotiklere karşı mikroorganizmaların hızla direnç geliştirmesi dünya çapında bilim insanlarının bu konu hakkında çalışmalarını arttırmasını gerektirmektedir. Ayrıca enfeksiyon tedavisinde çoklu antibiyotik direncine karşı başarı oranı gittikçe azalmaktadır. Bundan dolayı tıbbi bitkilerin antibiyotik geliştirmek ve ilaçlara alternatif olarak kullanılması önemini korumaya devam etmektedir.

Tek antibiyotikle öldürülemeyen mikroorganizmaların dirençliliğine karşı bitkilerde bulunan çok sayıda maddenin sinerjik etkisi kullanılarak daha etkin bir tedavi elde edildiği bildirilmiştir (Shanthi ve ark., 2010; Mohd Nazri ve ark., 2011). Bunun sonucunda, bitkilerden elde edilen antimikrobiyal ajanlarının etkilerinin araştırılması, araştırmacıların bu konu hakkında odaklanmalarını sağlamıştır (Dash ve ark., 2011).

Çok uzun yıllardır, bazı yaraların ve hastalıkların tedavisinde karayosunlarının kullanılması, türlerinin antimikrobiyal aktivite analizini; ilgili maddelerinin belirlenmesini ve saflaştırmasını; ilaç tasarımlarında kullanılmasını önemli hale getirir (Canl1, 2015). Antimikrobiyal etkisi analiz edilmek için kullanılan $P$. filiforme türünün etanol ekstraktları 17 bakteri ve 1 maya türüne karşı test edilmiştir.

\section{Materyal ve Metot}

2.1. Briyofit Örneği

P. filiforme örneği 2011 yılında Amasya Akdağ'da bulunan Boraboy gölünün kenarından toplanmıştır (Şekil 1). Şahit örnek Dokuz Eylül Üniversitesi bünyesinde saklanmaktadır.

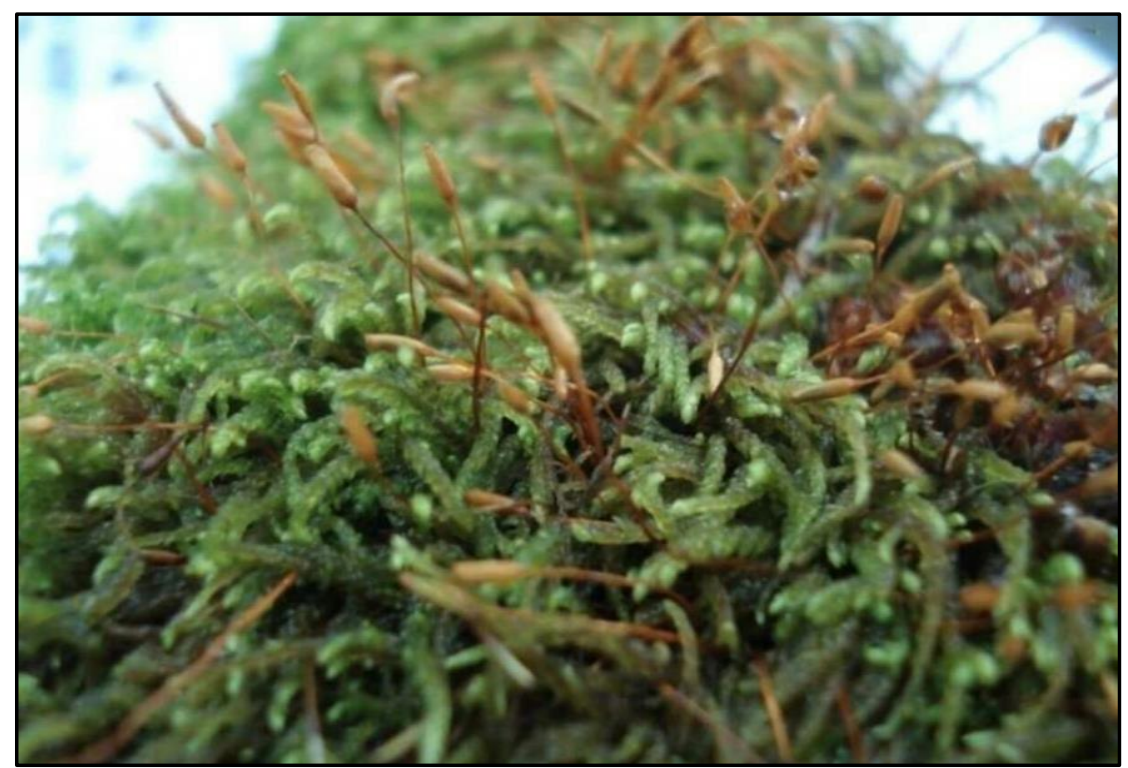

Şekil 1. Pterigynandrum filiforme'nin doğal ortamdaki görünüşü. 


\subsection{Ekstraksiyon yöntemi}

$P$. filiforme karayosunu örnekleri toplanıp kurutuldu ve öğüücü ile parçalanarak küçük parçalar haline getirildi. Toz haline gelen numuneler saf etanol (Sigma-Aldrich) içinde 140 ppm'de oda sıcaklığında 2 gün çalkalandı (Altuner ve ark., 2013). Bundan sonra, Whatman No.1 filtre kağıdıyla buharlaştırma balonlarına süzüldü. Filtratlar $45^{\circ} \mathrm{C}$ 'de bir döner buharlaştırıcı (Buchi R3) ile buharlaştırıldı (Canlı ve ark., 2016a). Son olarak, karayosunundan kalan tortunun ağırlığı ölçülüp tekrardan etanol emdirildi ve 0.27 ve $0.93 \mathrm{mg}$ örnek hazırlandı.

\subsection{Mikroorganizmalar}

P. filiforme'nin antimikrobiyal etkisini analiz etmek için geniş bir gram pozitif bakteri, gram negatif bakteri ve maya seçildi. Bu nedenle, 17 bakteri ve 1 maya türü kullanılmış ve bu mikroorganizmalar Nutrient Agar (BD Difco, ABD) üzerinde zenginleştirildi. Kullanılan suşların 11'i standart bakteri ve 1'i standart maya suşudur. Beş tanesi standart gram pozitif bakterilerdir ve bunlar Bacillus subtilis DSMZ 1971, Enterecoccus faecalis ATCC 29212, Listeria monocytogenes ATCC 7644, Staphylococcus aureus ATCC 25923 ve Staphylococcus epidermidis DSMZ 20044 türleridir. Diğerleri standart gram negatif bakterileridir ve bunlar Enterobacter aerogenes ATCC 13048, Escherichia coli ATCC 25922, Pseudomonas aeruginosa DSMZ 50071, Pseudomonas fluorescens P1, Salmonella enteritidis ATCC 13075 ve Salmonella typhimurium SL1344 türleridir. Candida albicans DSMZ 1386 olan 1 standart maya türü vardır. Ayrıca, Ankara Üniversitesi Mikrobiyoloji Laboratuvarı'ndan yiyeceklerden izole edilen 6 adet standart dışı bakteri çalışıldı. Bunlardan üçü, Enterococcus durans, Enterecoccus faecium ve Listeria innocua olan gram pozitif bakterilerdir. Diğerleri, Klebsiella pneumoniae, Salmonella infantis ve Salmonella kentucky olan gram negatif bakterilerdir.

\section{4. İnokulum hazırlama}

Tüm bakteri türü, $37^{\circ} \mathrm{C}^{\prime}$ de 24 saat, ancak $C$. albicans, $27^{\circ} \mathrm{C}^{\prime}$ de 48 saat inkübe edildi (Canlı ve ark., 2016b). Bakteriler için yaklaşık $10^{8}$
cfu.mL ${ }^{-1}$ ve $C$. albicans için $10^{7}$ cfu.mL $\mathrm{mL}^{-1}$ içeren inokülasyonu standartlaştırmak için her bakteri ve maya steril \% $0.9 \mathrm{NaCl}$ çözeltisi (serum fizyolojik) solüsyonuna aşlanarak 0.5 McFarland standardına getirilmiş bakteri örnekleri ile çalışma gerçekleştirildi (Altuner ve ark., 2014).

\subsection{Antimikrobiyal aktivite testi}

Etanol ekstraktının antimikrobiyal etkinlik Andrews (2003) tarafından tarif edildiği şekilde disk difüzyon testi ile gerçekleştirildi. Öncelikle, Mueller Hinton Agar (BD Difco, ABD) $4.0 \mathrm{~mm} \pm 0.5 \mathrm{~mm}$ 'lik bir derinliğe ulaşmak için $90 \mathrm{~mm}$ steril Petri kabına dökülmüsstür. 20 ve $70 \mu \mathrm{L}$ ekstrakt $6 \mathrm{~mm}$ Oxoid Antimikrobiyal Duyarlılık Test Disklerine yüklendi. Sonuçlara müdahale edebilecek kalan etanolü uçurmak için diskler gece boyunca steril koşullar altında $30^{\circ} \mathrm{C}^{\prime}$ de kurumaya bırakıldı. Bundan sonra, steril serum fizyolojiğe inoküle edilmiş hazır mikroorganizmalar petri kaplarının yüzeyini tamamen kaplayacak şekilde ekim yapıldı. Bu diskler oda sıcaklığında aseptik koşullar altında 5 dakika boyunca kurumaya birakıldı (Canlı ve ark., 2015). Daha sonra diskler yüzeye yerleştirilerek bakteriler inkübe edildikten sonra inhibisyon zonu çapları mm cinsinden ölçülüp kaydedildi.

\subsection{Kontroller}

Boş steril diskler ve ekstraksiyon solventi (etanol) negatif kontrol olarak kullanıldı.

\section{7. İstatistik}

İstatistiksel analiz, $\mathrm{p}=0.05$ olan tek yönlü varyans analizi olan non-parametrik bir yöntem olan Kruskal-Wallis kullanılarak yapıldı.

\section{Tartışma ve Sonuç}

$P$. filiforme etanol ekstraktının 17 bakteri ve 1 maya türüne karşı yapılan araştırma sonucunda Tablo 1 de görüldüğ̈̈ gibi 6 bakteri üzerinde etki saptand1. S. aureus $(10 \mathrm{~mm})$, B. subtilis $(8$ $\mathrm{mm})$, L. monocytogenes $(8 \mathrm{~mm})$ ve E. faecalis $(7 \mathrm{~mm})$ gram pozitif bakterileridir ve kullanılan karayosunu ekstraktının karşı hassas oldukları belirlendi. Gram negatif bakterilerden $K$. pneumoniae $(7 \mathrm{~mm})$ ve $S$. enteritidis $(7 \mathrm{~mm})$ türlerinde etki görüldü. 
Tablo 1. P. filiforme için disk difüzyon testi sonuçları ( $\mathrm{mm}$ cinsinden inhibisyon zonları).

\begin{tabular}{lcc}
\hline & $20 \mu \mathrm{L}$ & $70 \mu \mathrm{L}$ \\
\hline S. aureus ATCC 25923 & 8 & 10 \\
B. subtilis DSMZ 1971 & 7 & 8 \\
L. monocytogenes ATCC 7644 & 7 & 8 \\
E. faecalis ATCC 29212 & - & 7 \\
K. pneumoniae & - & 7 \\
S. enteritidis ATCC 13076 & - & 7 \\
C. albicans DSMZ 1386 & - & - \\
E. aerogenes ATCC 13048 & - & - \\
E. coli ATCC 25922 & - & - \\
E. durans & - & - \\
E. faecium & - & - \\
L. innocula & - & - \\
P. aeruginosa DSMZ 50071 & - & - \\
P. fluorescens P1 & - & - \\
S. epidermidis DSMZ 20044 & - & - \\
S. infantis & - & - \\
S. kentucky & - & - \\
S. typhimurium SL 1344 & - & - \\
\hline "-" Etki yok & &
\end{tabular}

S. aureus hastane enfeksiyonlarına yol açan en önemli patojendir ve yoğun bakım ünitelerinde olmak üzere metisiline dirençli $S$. aureus (MRSA) enfeksiyonları giderek artan oranlarda rapor edilmektedir (Richards ve ark., 1999). Yapılan bazı çalışmalarda, yoğun bakım ünitelerinden izole edilen $S$. aureus izolatlarının yaklaşık \%80'inin metisiline dirençli olduğu saptandı (Ippolito, 2010).

Uyar ve ark. (2016) tarafindan gerçekleştirilen çalışmada $T$. alopecurum karayosunu türünün $S$. aureus bakterisine karşı oluşturmuş olduğu zon 8 mm'dir. Aynı çalışmada C. cuspidata karayosunu türünün de $S$. aureus bakterisine karş1 gösterdiği zon $7 \mathrm{~mm}$ 'dir. P. filiforme'nin $S$. aureus türü bakteriye karş1 oluşturduğu zon 10 mm'dir. Bu nedenle $P$. filiforme' nin bu suş üzerindeki etkisi diğer çalışma ile karşılaştırıldığında oldukça yüksek bulundu.
P. filiforme'nin, L. monocytogenes'e karş1 en yüksek dozajda $8 \mathrm{~mm}$ zon oluşturduğu görüldü. L. monocytogenes antibiyotik direnci için günümüzde çok önemsenmese de sürekli ve yavaş bir direnç geliştirme mekanizmasının olduğu tespit edilmiş olup gelecekte hastane enfeksiyonları açısından büyük risk oluşturacağ 1 tahmin edilmektedir (Conter ve ark., 2009). $\quad P$. filiforme'nin, $L$. monocytogenes'e karşı saptanan antimikrobiyal etkisi bu nedenle ayrı bir önem taşımaktadır.

Çalışmanın sonucunda elde edilen etkilerin daha fazla madde miktarı ile gerçekleştirildiğinde daha büyük etkiler oluşabileceği tahmin edilmektedir. Aktif bileşiklerin farmakokinetik görünüşüne bağlı olan etki mekanizmasını ve antibiyotik etkileşimlerini belirlemek için daha fazla araştırmaya ihtiyaç duyulmaktadır.

\section{Kaynaklar}

Akbar A. Anal K.A. 2011. Food safety concerns and food-borne pathogens, Salmonella, Escherichia coli and Campylobacter. FUUAST Journal of Biology. 5:2, 5-17.

Altuner E.M. Canlı K. Akata I. 2013. Antimicrobial Screening of Calliergonella cuspidata, Dicranum polysetum and Hypnum cupressiforme. Journal of Pure and Applied Microbiology. 1:8, 539545.

Altuner E.M. Canlı K. Akata I. 2014. In vitro Antimicrobial Screening of Hedwigia ciliata Var. leucophaea and Determination of the Ethanol Extract Composition by Gas 
Chromatography/Mass Spectrometry (GC/MS). Journal of Pure and Applied Microbiology. 4:8, 2987-2998.

Andrews J.M. 2003. BSAC standardized disc susceptibility testing method (version 6). Journal of Antimicrobial Chemotherapy. 60, 20-41.

Canlı K. Akata I. Altuner E.M. 2016a. In vitro Antimicrobial Activity Screening of Xylaria hypoxylon. African Journal of Traditional, Complementary and Alternative medicines. 13:4, 42-46.

Canlı K. Altuner E.M. Akata I. 2015. Antimicrobial screening of Mnium stellare. Bangladesh Journal of Pharmacology. 10, 321-325.

Canlı K. Yetgin A. Akata I. Altuner E.M. 2016b. In vitro Antimicrobial Screening of Aquilaria agallocha Roots. African Journal of Traditional, Complementary and Alternative medicines. 13:5, 178-181.

Canlı K. Yetgin A. Akata I. Altuner E.M. (2016c). In vitro Antimicrobial Activity of Angelica sylvestris Roots. International Journal of Biological Sciences, 1:1, 1-7.

Conter M. Paludi D. Zanardi E. Ghidini S. Vergara A. Ianieri A. 2009. Characterization of antimicrobial resistance of foodborne Listeria monocytogenes. International journal of food microbiology. 128:3, 497-500.

Dash M. Chiellini F. Ottenbrite R.M. Chiellini E. 2011. Chitosan a versatile semi-synthetic polymer in biomedical applications. Progress Polymer Science, 36, 981-1014.

Erdoğan A.E. Everest A. 2013. Antimikrobiyal Ajan Olarak Bitki Bileşenleri. Türk Bilimsel Derlemeler Dergisi. 6:2, 27-32.

Ippolito G. Leone S. Lauria F.N. Nicastri E. Wenzel R.P. 2010. Methicillin-resistant Staphylococcus aureus: the superbug. International Journal of Infectious Diseases. 14:4, S7-11.

Iwu M.W. Duncan A.R. Okunji C.O. 1999. New antimicrobials of plant origin. Perspectives on new crops and new uses. ASHS Press, Alexandria, VA, 457-462.

Kahraman E.P. Karakeçe E. Erdoğan F. Uluyurt H. Köroğlu M. Çiftci İ.H. 2017. Klebsiella pneumoniae izolatlarının antibiyotiklere direnç durumlarının değerlendirilmesi. Ortadoğu Medical Journal. 9:1, 12-18,

Karou D. Nadembega W.M.C. Ouattara L. Ilboudo D.P. Canini A. Nikiema J.B. Simpore J. Colizzi V. Traore A.S. 2007. African Ethnopharmacology and New Drug Discovery. Medicinal and Aromatic Plant Science and Biotechnology. 1, 61-69.

Mohd Nazri N.A.A. Ahmat N. Adnan A. Syed Mohamad S.A. Syaripah Ruzaina S.A. 2011. In vitro antibacterial and radical scavenging activities of malaysian table salad. African Journal Biotechnology. 10, 5728-5735.

Richards M.J. Edwards J.R. Culver D.H. Gaynes R.P. 1999. Nosocomial infections in medical intensive care units in the United States: National Nosocomial Infections Surveillance System. Critical Care Medicine. 27, 887-892.

Shanthi Sree K.S. Yasodamma N. Paramageetham C.H. 2010. Phytochemical screening and in vitro antibacterial activity of the methanolic leaf extract: Sebastiania chamaelea Müell. The Bioscan. $5,173-175$.

Uyar G. Doğru N.H. Ören M. Çavuş A. 2016. Bazı Karayosunu Türlerinin (Cinclidotus riparius (Host ex Brid.) Arn., Calliergonella cuspidata (Hedw.) Loeske, Thamnobryum alopecurum (Hedw.) Gangulee, Leucobryum juniperoideum (Brid.) Müll. Hal., Cirriphyllum crassinervium (Taylor) Loeske \& M. Fleisch.) Antibakteriyel Aktivitesinin Belirlenmesi. Anatolian Bryology. 2, 1-8. 